\title{
Automated Smart Irrigation System Based on IoT
}

\author{
Bhavani $\mathrm{G}^{\mathrm{a}, 1}$, and Malathi $\mathrm{S}{ }^{\mathrm{b}}$ \\ ${ }^{a} P G$ Scholar, Dept of CSE, Panimalar engineering college, Chennai \\ ${ }^{b}$ Professor, Dept of CSE, Panimalar engineering college, Chennai
}

\begin{abstract}
India is an agricultural country with variety of crops. Water flow to the crop field is found important with accurate level. Multiple crops can be grown in single field with accurate water level. Water level need to be controlled due to water scarcity. Exact amount of water can be made to flow in the field through IoT techniques. Inorder to bring efficient crop growth and to avoid excess water flow, automation in agriculture can be done. Automation in agriculture can reduce excess water usage in water scarce and dry area. Automation is done with sensors and various IoT techniques to improve water level in agricultural field.
\end{abstract}

Keywords. IoT, Sensors

\section{Introduction}

Automation is the recent technology in various fields. Automation can be done in agriculture. Automation in agriculture brings about control of water flow and growth of multiple crops. Automation can be done through IoT technique. Various notification about the agricultural field can be given to the farmers. Farmers can also control the excess flow of water.

Agricultural irrigation can be done through various types. Types of irrigation includes about surface irrigation, drip irrigation, sprinkler irrigation etc. There can be certain advantages and disadvantages in various types of irrigation.

Agricultural irrigation can be done with various types of crops. Various types of crops can be grown in same field. Multiple types of crops require various amount of water flow. Water flow need to be measured with exact value to prevent water loss. Since, water is found to be very important, it can be used in agriculture with accurate level.

Water flow to agricultural field can also be controlled through sensors technology. Sensors can also be connected to IoT method. Sensors are connected with IoT for notification purpose top the farmers. Farmers can know about the field condition and climatic condition through various sensors. Various sensors include about soil moisture sensor, water level indicator etc.

Soil moisture sensor checks about condition of the soil like wet condition, dry condition etc. Water level indicator can be connected with water and soil and gives notification like presence or absence of water. Water level can check and detect about whether soil require water or not.

Various methods like artificial intelligence can also be used in agricultural field. Artificial intelligence include about automation. Automatic irrigation brings 
about various advantages. Recent water crisis in agriculture can overcome by automation. Water scarcity in certain areas can also be made with automation. The remaining portion of this paper include about various methodologies, modules and software method. Finally, the paper include about summary of this paper and future work.

\section{Related Works}

Abhilash Shrivastava, Rajesh M.,et al in [1] proposes Automatic irrigation system with data log creation. This paper proposes about right amount of water will provide about good yield. Automatic irrigation can be made with arduino and various sensors. The collected information can be given with data log.Various sensors like temperature, moisture etc are connected and mobile application is developed for notification purpose.

In [2], Kishor C, Sunil Kumar H U, et al have addressed about water usage approximation. Various technology like IoT, GPRS, ANN have been used. Temperature and moisture sensor are connected to the root zone of the plant and the condition of the plant is made notified.This method is made remote accessible by using GPRS technology. The paper proposed about saving of water.Smart Irrigation System Using Machine Learning and IOT by Revanth Kondaveti,

Akash Reddy in [3] shown about machine learning and IoT in smart irrigation. The paper gives about automation in irrigation and rainfall prediction system to grow a particular crop. Shetty Sagar, Kalha Ajit Singh [4] shown image processing and usage of sensors in agriculture. Due to inconsistent amount of rainfall, various methods like image processing can be used. Various values can be captured through image processing and it can also be stored in dataset and cloud. It is concluded with improvement in efficiency of the method with less water usage. Anusha Kumar, Aremandla Surendra [5] focus on irrigation based on IoT [6] and regression algorithm. Due to wastage of water, there is an increase in water scarcity. Inorder to overcome this, various IoT method is used. This paper also provide types of irrigation system in the field of agriculture. Regression algorithm can be used to detect the requirement of water. Wastage of water is controlled through various hardware and reduce human effort and energy.

\section{Proposed System}

Overall design of this paper include about sensors connected with software and IoT method. The paper include about variety of crops connected with sensors for limited use of water. Variety of crops like spinach, mint grown in a separate path in a single field. Water flow for the crops can be given through pipe connection. Water content for various crops require with different water content. Some crop requires more water level than the other crop. Various level of water is connected with sensors and updated with software. When the water level exceeds, motor connected with the crop stops immediately through automation and the level meets the required level. Exact amount of water can be useful in a water scarce region. Water wastage can also be reduced in the field of agriculture by using this method. Irrigation management can achieve various water control mechanism. Various climatic change and weather conditions must be checked with irrigation field. Climatic change may also include about water 
level for growth of plants. Moisture sensor detects about soil condition and presence of water content in the field. Liquid controller checks about water content and stops the flow of excess water to the field. Overall design of the system is connected to the software module. Software is updated with hardware system and flow of water is monitored. Water level is informed or made notified to the farmers through Thing speak and Iot. Internet of Things is the latest technology which is made connected with agriculture.

\subsection{Soil Moisture Sensor}

Detects about the soil condition and controls the flow of water into the field. Irrigation field can be connected with various soil sensors and water flow can be controlled to variety of crops with certain different value.

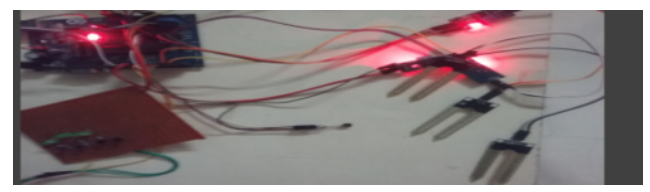

Figure 1. Soil moisture sensors

\subsection{Liquid Flow Controller}

Liquid flow controller can check the water level and control the flow of water into the field. water level for various crop varies and liquid flow controller can pass the water into the field accordingly.

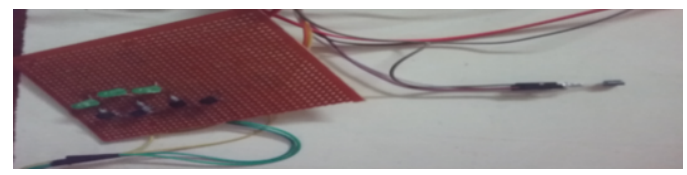

Figure 2. Water flow controller

\subsection{LCD Display}

Moisture level and Temperature level can be detected and displayed in LCD display. LCD display values can be made notified to the farmers.

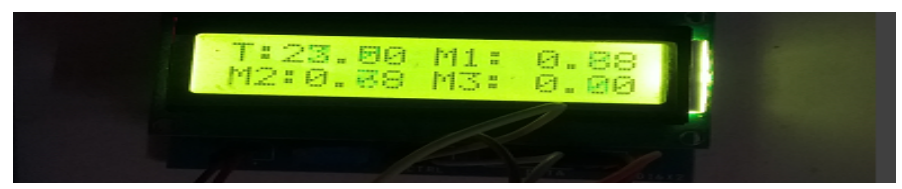

Figure 3. LCD Display 


\subsection{Various Method For Water Detection}

Soil testing is done in field through soil moisture sensor. Presence of enough water level in the field control the flow of water.

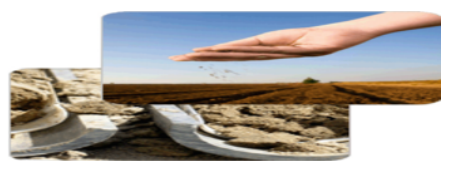

Figure 4. Soil Testing

Climatic conditions can be monitored using constructing weather station in the field. Weather can detect about requirement of water in the field based on vapour present in the field.

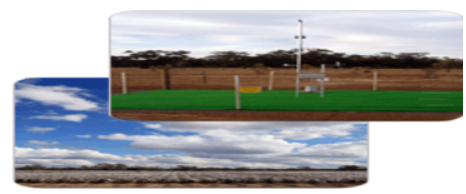

Figure 5. Weather Stations

\subsection{Advantages And Disadvantages In Water Control In Agriculture}

Various advantage and disadvantages can be found in water control in agriculture. Advantage include about exact amount of water flow in the field of agriculture which will be useful to control wastage of water. Water scarce region can be made beneficial by using automation of sensors in agricultural field. Disadvantage include about they may occur some automation problem and some misfunctioning of sensors and several hardware problems.

\section{Conclusion And Future Work}

Agricultural irrigation has been done with water control and automation in sensors. Several advantage can be done with improvement in artificial intelligence. In future, the control of water can be extended and done with large acres of land with large variety of crops.

\section{References}

[1] 1. Abhilash Shrivastava, Rajesh M., Automatic Irrigation System with Data Log Creation.International Conference on Inventive Communication and Computational Technologies, (ICICCT 2018), CFP18BAC-ART; ISBN:978-1-5386-1974-2.

[2] Kishor C, Sunil Kumar H U,Water usage approximation of Automated irrigation system using IoT and ANN's.Internatiuonal conference on I-SMAC,2018, ISBN:978-1-5386-1442-6.

[3] Revanth Kondaveti, Akash Reddy,Smart Irrigation System Using Machine Learning and IOT.International Conference on Vision Towards Emerging Trends in Communication and Networking, 978-1-5386-9353-7/19/\$31.00 (C2019 IEEE.

[4] Shetty Sagar, Kalha Ajit Singh, Enhanced Agriculture using Image Processing and Sensors. 2018 IEEE International Students' Conference on Electrical, Electronics and Computer Science, 978-1-5386-26634/18/\$31.00 C2018 IEEE. 
[5] Anusha Kumar, Aremandla Surendra, Internet of Things Based Smart Irrigation Using Regression Algorithm. 2017 International Conference on Intelligent Computing,Instrumentation and Control Technologies, 978-1-5090-6106-8/17/\$31.00 C2017 IEEE.

[6] V.D.Ambeth Kumar, G.Saranya , D.Elangovan, V.RahulChiranjeevi, V.D.Ashok Kumar, "IOT Based Smart Museum Using Wearable Device", Lecture Notes in Networks and Systems, Vol.55, pp: 33-42, 2018. 